\title{
Tetralogy of fallots with quadrivalvular stenosis: a rare coexistence
}

\author{
Sudarshan Kumar Vijay, ${ }^{1}$ Bhuwan Tiwari, ${ }^{1}$ Mukul Misra, ${ }^{1}$ Gaurav Raj ${ }^{2}$
}

${ }^{1}$ Department of Cardiology, Dr Ram Manohar Lohia Institiute of Medical Sciences, Lucknow, Uttar Pradesh, India

${ }^{2}$ Department of Radiodiagnosis, Dr. Ram Manohar Lohia Institiute of Medical Sciences, Lucknow, Uttar Pradesh, India

\section{Correspondence to}

Dr Sudarshan Kumar Vijay, skvijay1980@rediffmail.com

Accepted 3 April 2014

\section{DESCRIPTION}

A 30-year-old woman presented to us with a history of effort dyspnoea, palpitations and recurrent syncope. Her physical examination showed central cyanosis with clubbing of fingers and precordial auscultation revealed an ejection systolic murmur present in the left and right second intercostal spaces with the presence of middiastolic murmur at the apex and left parasternal area. The chest X-ray posteroanterior view revealed cardiomegaly with increased vacular marking (figure $1 \mathrm{~A}$ ). The twodimensional (2D) transthoracic echocardiogram parasternal long axis view showed large perimembranous ventricular septal defect (VSD) and overriding of aorta with thickened and calcified aortic leaflets (figure 1B and video 1). Colour Doppler examination showed bidirectional flow across VSD, moderate mitral regurgitation (video 2) and moderate aortic regurgitation. The calculated mitral valve area by planimetry was $1.0 \mathrm{~cm}^{2}$ (figure 1C; gradient 21/10). The continuous wave Doppler examination showed the presence of severe infundibular pulmonic stenosis (peak gradient $158 \mathrm{~mm} \mathrm{Hg}$; figure 2A), severe tricuspid stenosis (mean gradient $8 \mathrm{~mm} \mathrm{Hg}$; figure 2B and video 3 ) and severe aortic stenosis (peak velocity $4.1 \mathrm{~m} / \mathrm{s}$; figure $2 \mathrm{C}$ ). The continuity equation showed an aortic valve area of $0.7 \mathrm{~cm}^{2}$ and the pressure half-time method (PHT) showed a tricuspid valve area of $0.9 \mathrm{~cm}^{2}$ (PHT $206 \mathrm{~ms})$. Transoesophageal echocardiographic (TEE) exmination confirmed all findings and clearly showed a bifurcating jet of moderate aortic regurgitation which filled both the ventricles (figure $3 \mathrm{~A}$ and video 4). 3D TEE provided an en face view of

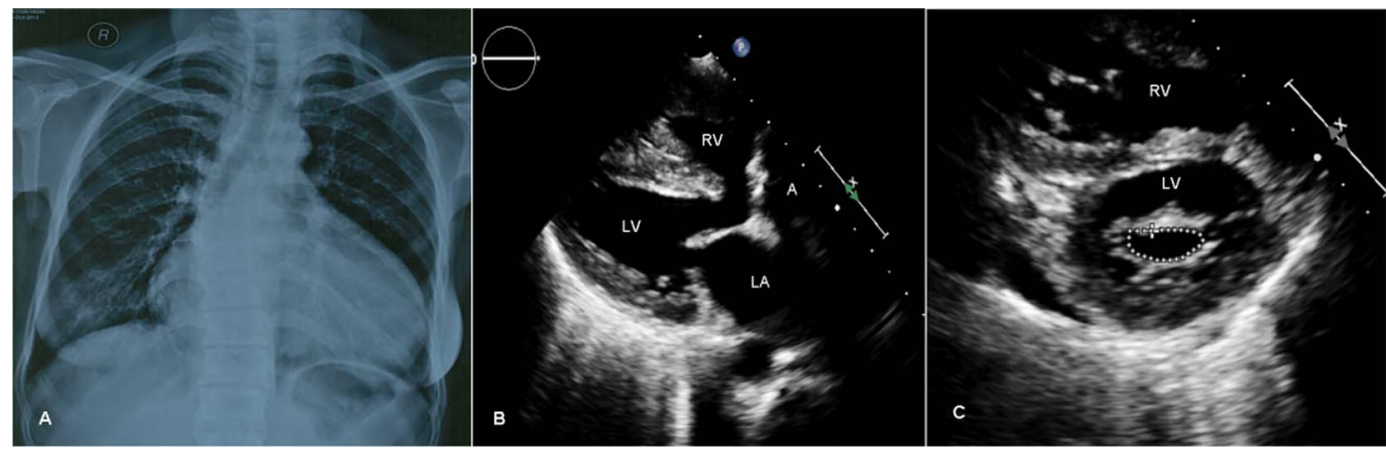

Figure 1 (A) Chest X-ray posteroanterior view showing cardiomegaly with increased vascular markings. (B) Two-dimensional transthoracic echocardiogram paratsernal long axis view showing large perimembranous VSD with thickened aortic leaflets. (C) Two-dimensional echocardiogram parasternal short axis view showing severe mitral stenosis by planimetry. A, aorta; LA, left atrium; LV, left ventricle; MV, mitral valve; RA, right atrium; RV, right ventricle; VSD, ventricular septal defect; TV, tricuspid valve.

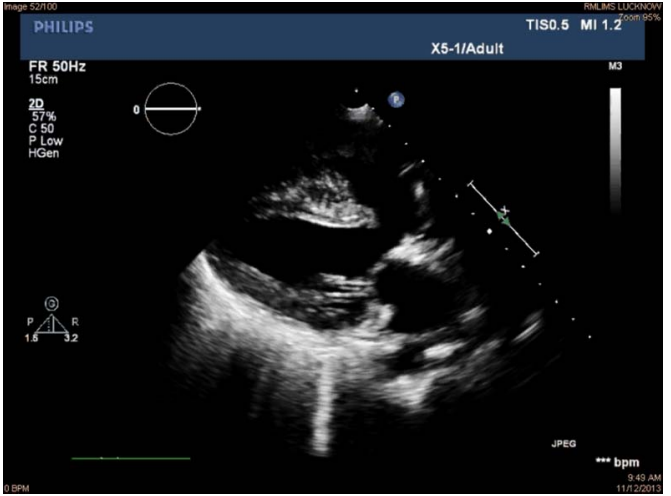

Video 1 2D transthoracic echocardiogram paratsernal long axis view showing large perimembranous VSD with thickened and severely calcified aortic leaflets and restrcited opening of mitral leaflets.

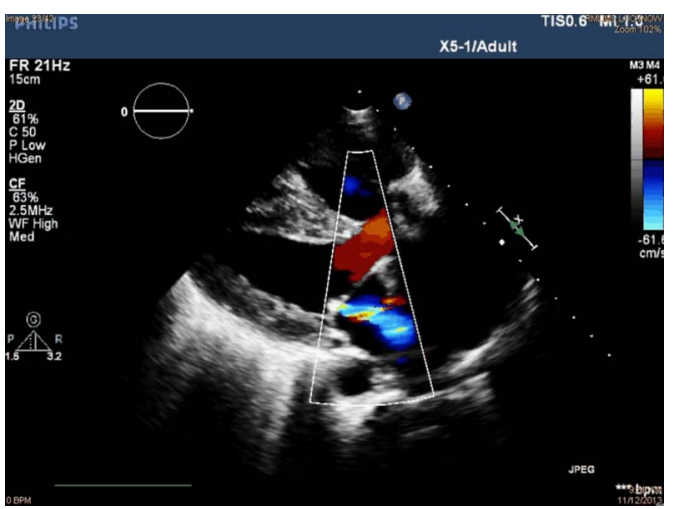

Video 2 The colour Doppler examination showing bidirectional flow across VSD, with moderate mitral regurgitation. 


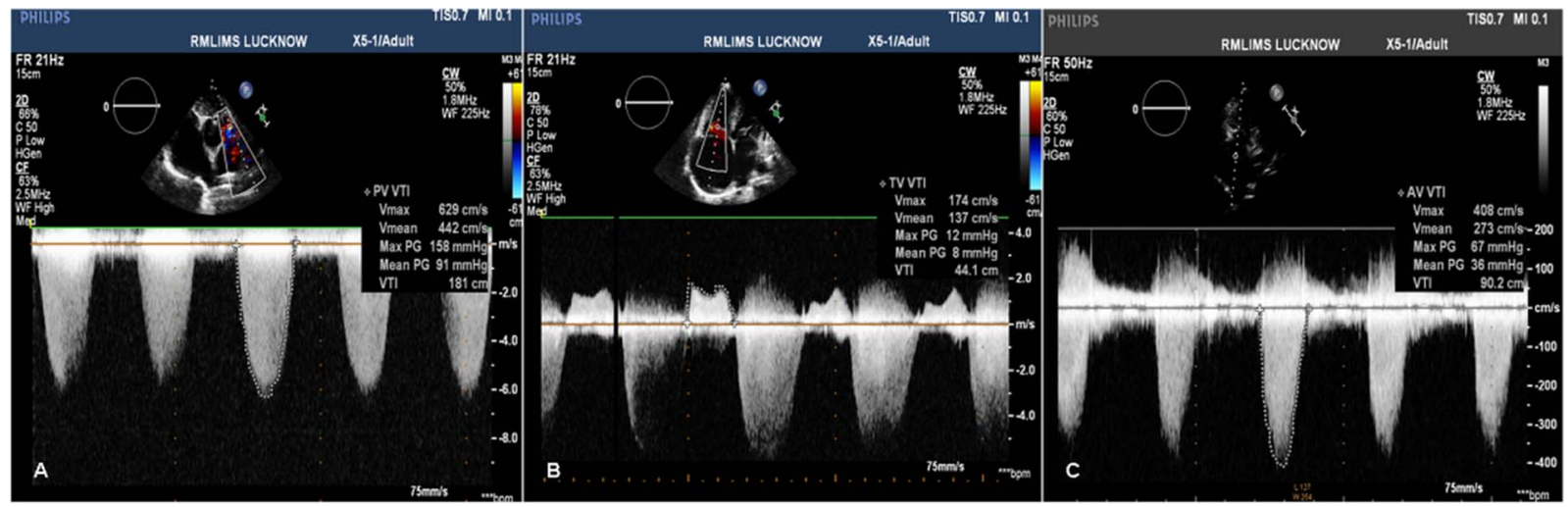

Figure 2 Application of continuous wave Doppler across various valves showing severe: (A) infundibular pulmonic stenosis, (B) tricuspid stenosis and (C) aortic stenosis.

stenosis of mitral and tricuspid valves (figure 3B). Sixty-four slice CT angiography showed normal coronaries with dilated pulmonary veins and its tributaries and there was no evidence of major aortopulmonary collaterals. With the diagnosis of tetralogy of fallots (TOFs) with quadrivalvular stenosis, the patient was referred for surgical correction.

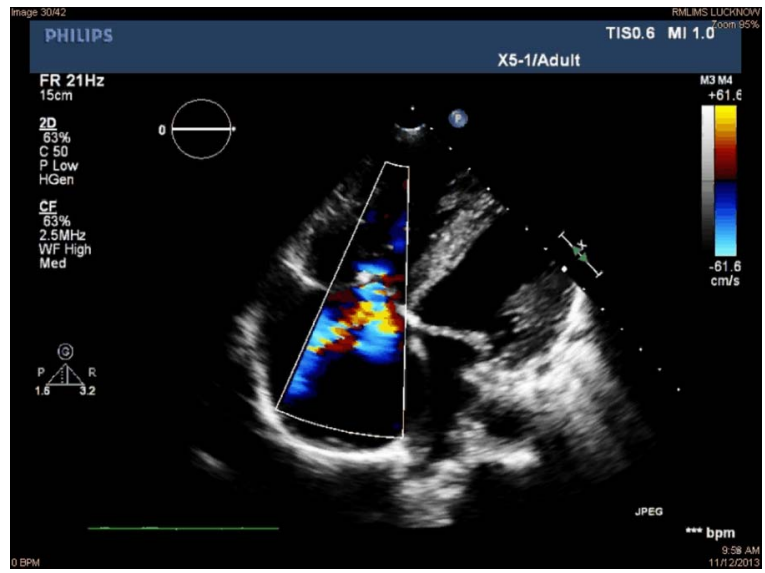

Video 3 Colour Doppler echocardiogram (Apical 4-chamber view) showing turbulent jet of tricuspid stenosis and regurgitation.
The rheumatic heart disease and congenital heart disease are two different pathophysiological entities, which infrequently coexist together. Whether the occurrence of rheumatic heart disease in congenital heart disease is merely a conincidence or whether congenital heart disease predisposes to rheumatic heart disease is still not clear. ${ }^{1}{ }^{2}$ The simultaneous stenosis of all

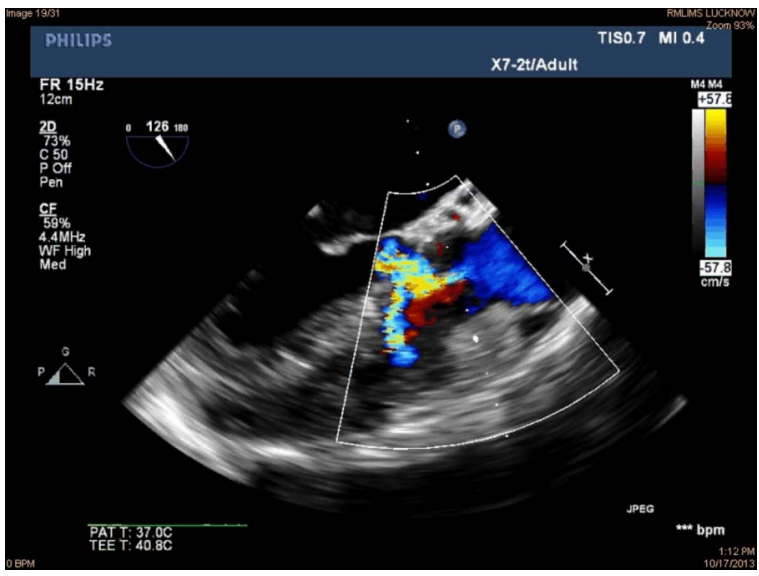

Video 4 2D TEE colour Doppler echocardiogram showing bifurcating jet of aortic regurgitation filling both ventricles.

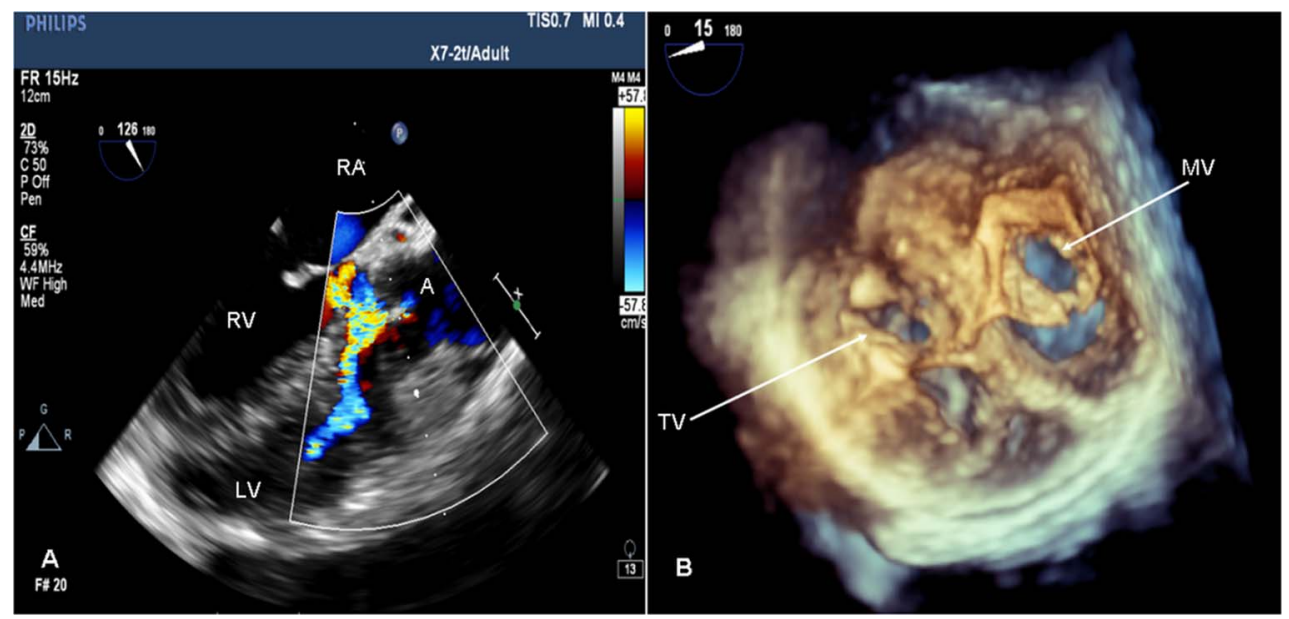

Figure 3 (A) Two-dimensional TEE showing a bifurcating jet of aortic regurgitation. (B) Three-dimensional TEE providing an en face view of stenosis of mitral and tricuspid valves. $A$, aorta; LA, left atrium; LV, left ventricle; MV, mitral valve; RA, right atrium; RV, right ventricle;TEE, transoesophageal echocardiogram; TV, tricuspid valve. 
ventricular inflow and outflow valves is rarely described in the literature. ${ }^{3}$ In our case, stenosis of the mitral, aortic and tricuspid valve occurred due to rheumatic aetiology, superimposed on the congenital infundibular pulmonic stenosis of TOF, which is probably the first case of its kind described in the literature.

\section{Learning points}

- Careful screening for the presence of rheumatic heart disease in congenital heart disease is required, which can exist in the overt form or with subtle valvular involvement.

- Presence of coexisting valvular lesions changes the haemodynamics in tetralogy of fallots, which can lead to changes in classic symtomatology and roentgenographic findings.

- Comprehensive echocardiographic and multimodality approach is necessary in defining multiple valvular lesions.
Contributors SKV and BT prepared the manuscript and MM and GR edited the manuscript.

Competing interests None.

Patient consent Obtained.

Provenance and peer review Not commissioned; externally peer reviewed.

\section{REFERENCES}

1 Bokhandi SS, Tullu MS, Shaharao VB, et al. Congenital heart disease with rheumatic fever and rheumatic heart disease: a coincidence or an association?. J Postgrad Med 2002;48:238-8.

2 Vijay SK, Tiwari B, Misra M, et al. Juvenile rheumatic mitral stenosis in association with perimembranous ventricular septal defect in a 3-year-old boy. BMJ Case Rep. Published online: 22 Nov 2013. doi:10.1136/bcr-2013-200560.

3 Jai Shankar K, Jaiswal PK, Cherian KM. Rheumatic involvement of all four cardiac valves. Heart 2005;91:e50.

Copyright 2014 BMJ Publishing Group. All rights reserved. For permission to reuse any of this content visit

http://group.bmj.com/group/rights-licensing/permissions.

BMJ Case Report Fellows may re-use this article for personal use and teaching without any further permission.

Become a Fellow of BMJ Case Reports today and you can:

- Submit as many cases as you like

- Enjoy fast sympathetic peer review and rapid publication of accepted articles

- Access all the published articles

- Re-use any of the published material for personal use and teaching without further permission

For information on Institutional Fellowships contact consortiasales@bmjgroup.com

Visit casereports.bmj.com for more articles like this and to become a Fellow 